ISSN 1112-9867

http://www.jfas.info

\title{
ASSESSMENT ON PATTERN OF URBAN AIR QUALITY BY USING CHEMOMETRIC TECHNIQUE: A CASE STUDY IN KOTA KINABALU, SABAH
}

\author{
S. M. Hanapiah, A. S. M. Saudi ${ }^{*}$ and Z. I. Rizman ${ }^{2}$ \\ ${ }^{1}$ Faculty of Environmental Healthcare, University Kuala Lumpur (UniKL) MESTECH, \\ Kajang, Selangor, Malaysia \\ ${ }^{2}$ Faculty of Electrical Engineering, UniversitiTeknologi MARA, 23000 Dungun, Terengganu, \\ Malaysia
}

Published online: 05 October 2017

\begin{abstract}
The study evaluate the relationship between the main daily concentrations of criteria air pollutants in urban areas and their associations by using chemometric technique. Data were gathered from the Department of Environmental for three years observations (2011-2013) consisting of 5 major pollutants such as $\mathrm{SO}_{2}, \mathrm{NO}_{2}, \mathrm{O}_{3}, \mathrm{CO}$ and $\mathrm{PM}_{10}$ and meteorological parameters such as wind direction, wind speed, temperature and humidity were used. Chemometric technique such asPCA and SPC were used in this study.It can be concluded that Chemometric technique is meaningful tool for assessment of large and complex air quality data. Besides, it also able to give a clear picture about trends, pattern of major air pollutants and sources identification of pollutants in the study area. This is important for a better management of air quality in the future which able to reduce the possible health and environmental effect.
\end{abstract}

Keywords: urban air quality; chemometrictechnique; Kota Kinabalu; Sabah.

Author Correspondence, e-mail: ahmadshakir@unikl.edu.my

doi: http://dx.doi.org/10.4314/jfas.v9i4s.49 


\section{INTRODUCTION}

The world is changing every day, the planning of urban world has brought a huge impact towards the environment and health. The increase number of human population, urban areas will have various kinds of activities that contributed to the higher rate of pollutants compared to areas with less development [1].Nevertheless, the environmental changes [13] associated with urbanization were something significant during last century and expected to continue through the next several decades [2]. Regardless of that, the distribution of the air pollutants could be influenced by wind and geographical factors. In Malaysia, the Air Pollutant Index has been used as an indicator of air quality since 1998. The API value based on the five sub-index criteria of air pollutants listed by Malaysian Department of Environmental (DOE) which are sulphur dioxide $\left(\mathrm{SO}_{2}\right)$, nitrogen dioxide $\left(\mathrm{NO}_{2}\right)$, carbon monoxide $(\mathrm{CO})$, particulate matter with 10-micron $\left(\mathrm{PM}_{10}\right)$ size in diameter and ground-level ozone $\left(\mathrm{O}_{3}\right)$. The highest sub-index [14] value of the individual pollutants is taken as the API value and more likely to cause significant damages to health, environment and property[3]. In [10] has reported the capital of Sabah, Kota Kinabalu is a place of rapid and dynamic change, where the situation is characterized by change and transition. As the turn of new century, any undergoing development and expansion into previously undeveloped lands will go through the challenges related to the environment. The main obstacles in solving this problems, Malaysia has been facing the very limited of strategy on management of air quality and controlling the point and non-point sources of pollutants. To prevent the situation from deteriorating in the long term period, the operation and maintenance tools for measuring the parameters of air quality are costly, so it is more convenient to apply the chemometrics method to identify the sources of pollution. Therefore, this study will be conducted to evaluate the urban growth and air quality status in Kota Kinabalu, Sabah by using the application of chemometrictechniques which have proven as priceless tools for developing the efficient management of the air monitoring network [4].

\section{METHODOLOGY}

The sampling station used in this study is namely as Kota Kinabalu air monitoring station (Latitude: $06^{\circ} 05^{\prime} 30^{\prime} \mathrm{N}$; Longitude: $116^{\circ} 07^{\prime} 30^{\prime \prime} \mathrm{E}$ ). Five air pollutants and four meteorological 
parameters including carbon monoxide $(\mathrm{CO})$, ozone $\left(\mathrm{O}_{3}\right)$, particulate matter $\left(\mathrm{PM}_{10}\right)$, sulfur dioxide $\left(\mathrm{SO}_{2}\right)$, nitrogen dioxide $\left(\mathrm{NO}_{2}\right)$, wind speed, wind direction, humidity and temperature are obtained from the Department of Environment Malaysia covering from 2011 to 2013 (3years) collected and monitored by the authorized private company, AlamSekitar Malaysia Sdn. Bhd. (ASMA) for the DOE. The air quality data were gathered from January 2011 to December 2013. The prediction model was developed using 214,440 datasets $(26,305$ observations 9 parameters). Less than $10 \%$ of missing data were found from the overall data and then the nearest neighbor method was applied for estimation of missing values based on the endpoints of the gaps using Equation (1)

$y=y 1$ if $x \leq x 1+[x 2-x 12]$ or $y=y 2$ if $x>x 1+[(x 2-x 1) / 2]$

where ' $y$ ' represents the interpolate, ' $\mathrm{x}$ ' is the time point of the interpolate, ' $y_{-} 1$ ' and ' $\mathrm{x}_{-} 1$ ' are the coordinates of the starting point of the gap and ' $\mathrm{y}_{-} 2$ ' and ' $\mathrm{x} \_2$ ' ' are the end points of the gaps.

Furthermore, in [5] stated that the PCs with eigenvalues more than 1 are considered significant in the varimaxrotations analysis in order to obtain new groups of variables (varimax factors, VFs). The PCs can be calculated as Equation (2)

$z i j=\alpha i 1 \times 1 j+\alpha i 2 \times 2 j+\alpha i 3 \times 3 j+\cdots+\alpha i m \times m j$

where ' $z$ ' is component score, ' $\alpha$ ' is component loading, ' $x$ ' is the measured value of variables, ' $\mathrm{i}$ ' is the component number, ' $\mathrm{j}$ ' is the sample number and ' $\mathrm{m}$ ' is the total number of variables. In this study, SPC is applied to determine the most significant pollutant that abundant may influence the air quality status in Kota Kinabalu. The SPC typically involves two phases. Generally, the first period of data analysis is used for estimating the population means and establishing the tentative or trial upper control limit (UCL) and lower control limit (LCL) [6].

\section{RESULTS AND DISCUSSION}

\subsection{Correlation of the Major Air Pollutant, Meteorological Parameter and Air Pollution Index (API)}

The Spearman's correlation test was used in the beginning of the PCA to determine the correlation between the air pollutants, meteorological and API factor. In this study, the coefficient correlation ( $\mathrm{r}$ ) is considered as low correlation if the r-value between 0.0 to 0.49 , 
0.5 to 0.69 as moderate correlation and 0.7 to 1.0 as high correlation. The API correlation coefficient between air pollutant concentration and Meteorological was not very high. From the result, it showed that API has low coefficient correlation between the PM10 (r-value = 0.459). This indicate that dispersion of the particulate matter in the study area relatively weak compared to other variables and it is normal to carry out daily life activities for all groups of peoples. Moreover, $\mathrm{PM}_{10}$ relatively showed high correlation between $\mathrm{CO}(\mathrm{r}$-value $=0.736$ ). This result illustrated that dispersion of $\mathrm{CO}$ from the fossil fuel combustion has been primarily related in Kota Kinabalu, particularly near to roadsides and intersections which also affected by other factors including traffic density, vehicle type and vehicle composition. While, the relationship between $\mathrm{PM}_{10}$ and $\mathrm{NO}_{2}$ shows the moderate correlation (r-value $=0.686$ ). However, most of the meteorological parameters shows not strong correlation or insignificant between the pollutants. According to [11], the area of city that surrounded by mountain and hill shows the weak correlation between air pollutant and meteorological parameters hence the location of Kota Kinabalu city that near to Crocker Range slightly influence the insignificant between the variables. Thus, the high correlation between $\mathrm{NO}_{2}, \mathrm{CO}$ and $\mathrm{PM}_{10}$ become positive in hot conditions because of the high temperature produced the formation of the pollutants [7].

Table 1. Correlation matrix

\begin{tabular}{|c|c|c|c|c|c|c|}
\hline Variables & $\mathrm{SO}_{2}$ & $\mathrm{NO}_{2}$ & $\mathrm{O}_{3}$ & $\mathrm{CO}$ & $\mathbf{P M}_{10}$ & API \\
\hline $\mathrm{SO}_{2}$ & 1 & -0.264 & -0.448 & -0.291 & -0.295 & -0.037 \\
\hline $\mathrm{NO}_{2}$ & -0.264 & 1 & 0.180 & 0.840 & 0.686 & 0.132 \\
\hline $\mathrm{O}_{3}$ & -0.448 & 0.180 & 1 & 0.199 & 0.288 & 0.132 \\
\hline co & 0.302 & -0.291 & 0.840 & 1 & $0.736^{x}$ & 0.197 \\
\hline $\mathbf{P M}_{10}$ & -0.295 & $0.686^{x-1}$ & 0.288 & $0.736^{x}$ & 1 & 0.459 \\
\hline API & -0.037 & 0.132 & 0.132 & 0.197 & 0.459 & 1 \\
\hline
\end{tabular}

$* *$ Correlation is significant at $\mathrm{p}<0.001, \mathrm{WS}=\mathrm{Wind}$ speed, $\mathrm{WD}=$ Wind direction, $\mathrm{AT}=$ Ambient Temperature, $\mathrm{H}=$ Humidity

\subsection{Source Identification of Air Pollutants}

\subsubsection{Varimax factor 1}

The first varimax factor (VF1) accounts for $28.923 \%$ of total variance that contribute the strong positive loadings of $\mathrm{NO}_{2}(0.818), \mathrm{CO}(0.857)$ and $\mathrm{PM}_{10}(0.905)$. In the study area, the 
highest concentration on $\mathrm{NO}_{2}$ related to the location where it surrounded by many industries, residential and commercial area. Furthermore, Kota Kinabalu also located near to the international and domestic airport. Hence, the aircraft emissions relatively contributes to the presence of $\mathrm{NO}_{2}, \mathrm{PM}_{10}$ and black carbon (BC) [3].The second factor that contributes to the strong positive loading is CO (0.857). Kota Kinabalu city also located by the South China Sea and many activities that involved the use of engine boat among the citizen that slightly contributes to the emission of $\mathrm{CO}$. As mentioned by [12] in their study, the emission of $\mathrm{CO}$ that yielded from the incomplete combustion inside the motor vehicles mainly contributes $95 \%$ of air pollution in several urban areas in Malaysia. In [10]has stated in their report even though air quality status in Sabah is good, every now and then during the occasional periods of forest fires outbreak during the dry season, it may contributes to the high concentration of $\mathrm{PM}_{10}, \mathrm{CO}$ and $\mathrm{O}_{3}$.

\subsubsection{Varimax factor 2}

The second varimax factor (VF2) explains $53.240 \%$ of total cumulative variance and showing the positive strong factor loading on ambient temperature $(0.904 \%)$ and negative strong factor loading on humidity $(-0.888)$. The result shows that temperature and humidity have a reverse relationship, in that higher temperature value will give a low value for humidity. Due to the land uses development such as construction area and residential area reduce the number of tress, which turn the increases the surrounding temperature [3].Fig. 1 shows the factor loading plot after varimax rotation. 


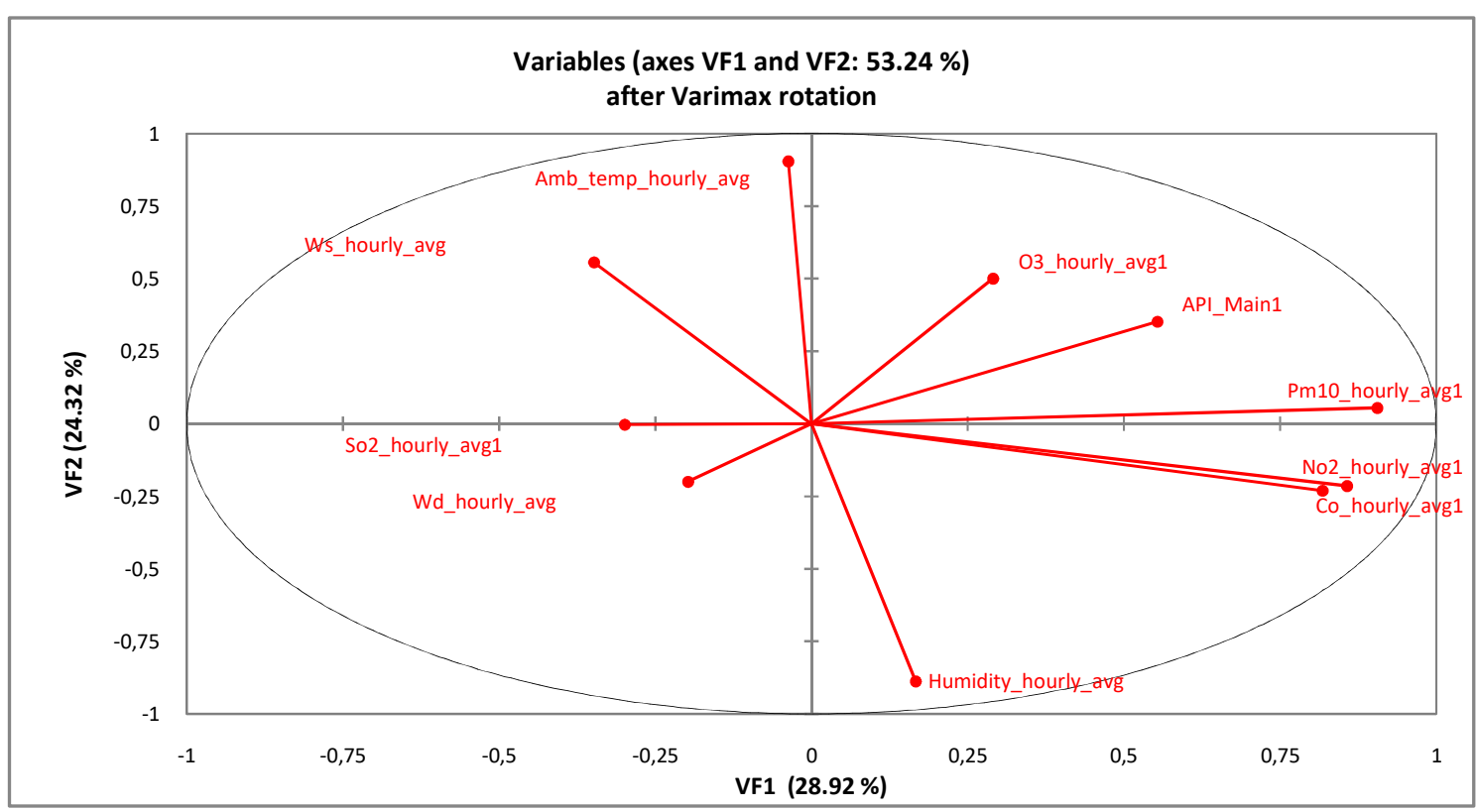

Fig.1. The factor loading plot after varimax rotation

\subsection{Pattern Recognition and Sources Identification of Air Pollutants}

The Statistical control chart were primarily developed for quality management of manufacturing processes. However, by using the statistical process control (SPC), individual chart allow to studies variation in individual sample over a time. Fig. 2 illustrated the daily trends (daily/24 hour averaging time) of CO in Kota Kinabalu city from 2011 to 2013. The control limit (CL) in the study area was $0.631 \mathrm{ppm}$ with Upper Control Limit (UCL) and Lower Control Limit between $0.915 \mathrm{ppm}$ to $0.347 \mathrm{ppm}$. The highest value of CO was on the 1st March 2012(37.00 ppm), which due to the high emission of $\mathrm{CO}$ from the incomplete combustion of fossil fuels in the motor vehicle. Motor vehicle and traffic flow were one of the major factor that have been identified as contributing to the higher level of $\mathrm{CO}$ in the Kota Kinabalu at the major intersections and busiest link in the city [8]. Fig. 3 illustrated the daily trends of PM10(24 hour averaging time) of PM10 in Kota Kinabalu, Sabah from year 2011 to 2013. The CL value of the PM10 was $47.304 \mathrm{ug} / \mathrm{m}^{3}$ with the UCL and LCL between the $68.463 \mu \mathrm{g} / \mathrm{m}^{3}$ to $26.146 \mu \mathrm{g} / \mathrm{m}^{3}$.However, in this study the highest concentration of PM10 is observed during the southeast monsoon. Thus, the higher value during the period mainly due to the drier weather condition, stable atmosphere, local effects and also transboundary transport of air pollutants from the neighboring countries [9]. Fig. 4 illustrated the daily trend 
of $\mathrm{NO}_{2}$ (daily averaging time) in Kota Kinabalu from 2011 to 2014. The $\mathrm{CL}$ value of $\mathrm{NO}_{2}$ was $0.009 \mathrm{ppm}$ with UCL and LCL between $0.013 \mathrm{ppm}$ to $0.005 \mathrm{ppm}$. The highest value of NO2 was on 24th January 2011 and keep fluctuates throughout the years. This was probably due to the emission from the motor vehicles as the Kota Kinabalu is the main city in Sabah. Another main source of $\mathrm{NO}_{2}$ also comes from the industrial processes, open burning, long range transport of pollutant and domestic fuel sources [7].

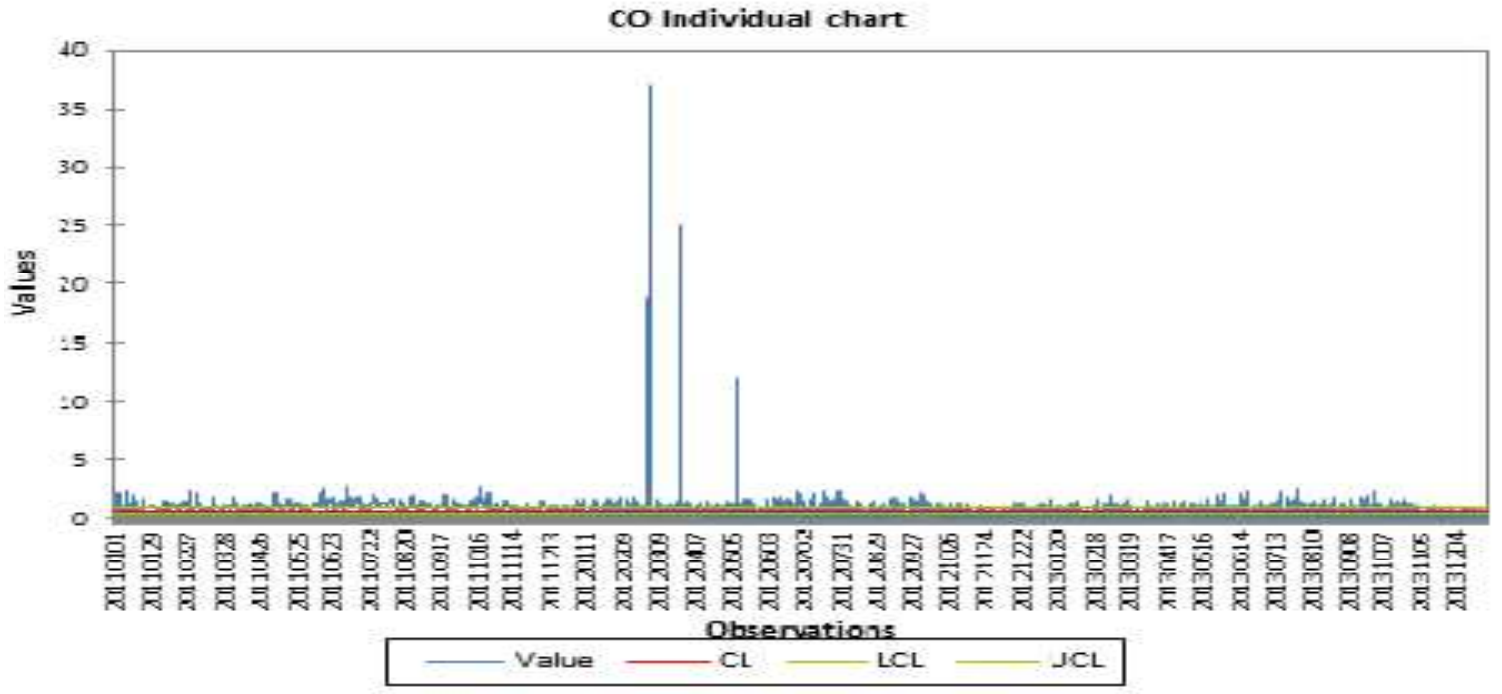

Fig.2. Control chart of CO for Kota Kinabalu (2011-2013)

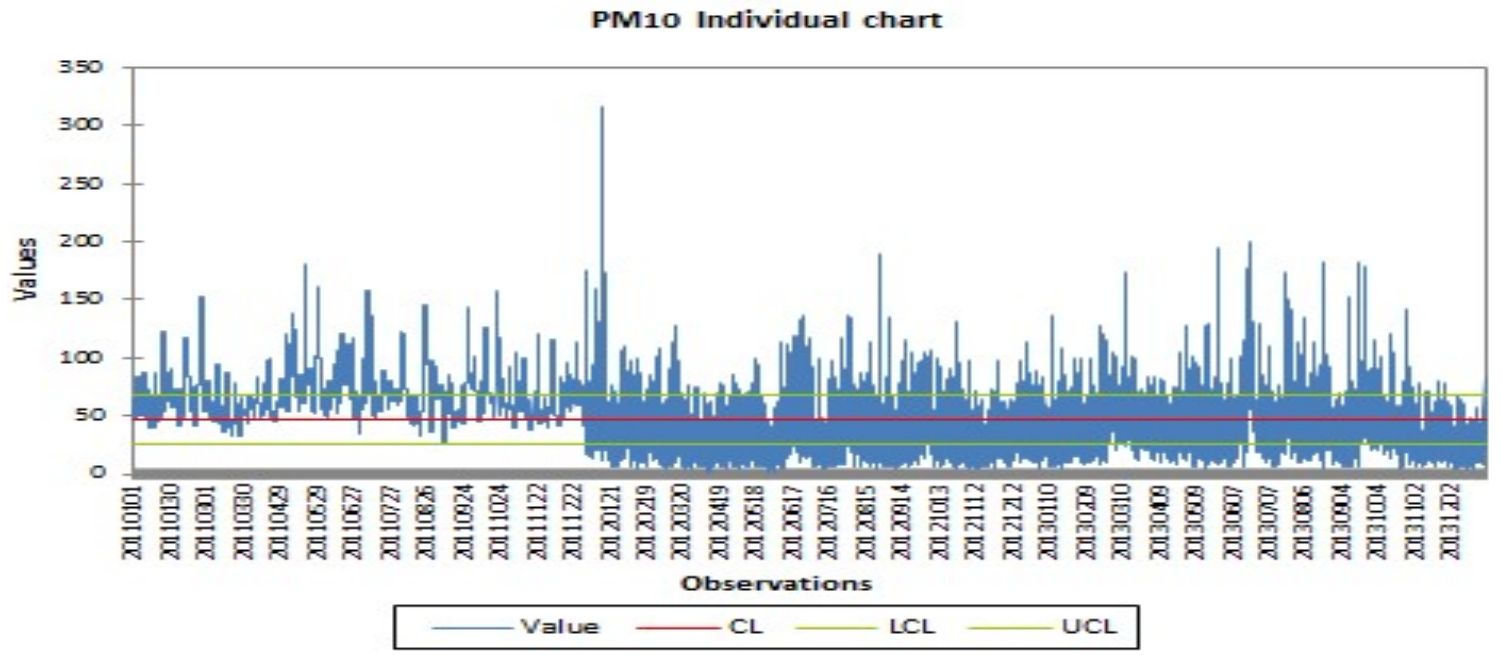

Fig.3. Control chart of $\mathrm{PM}_{10}$ for Kota Kinabalu (2011-2013) 


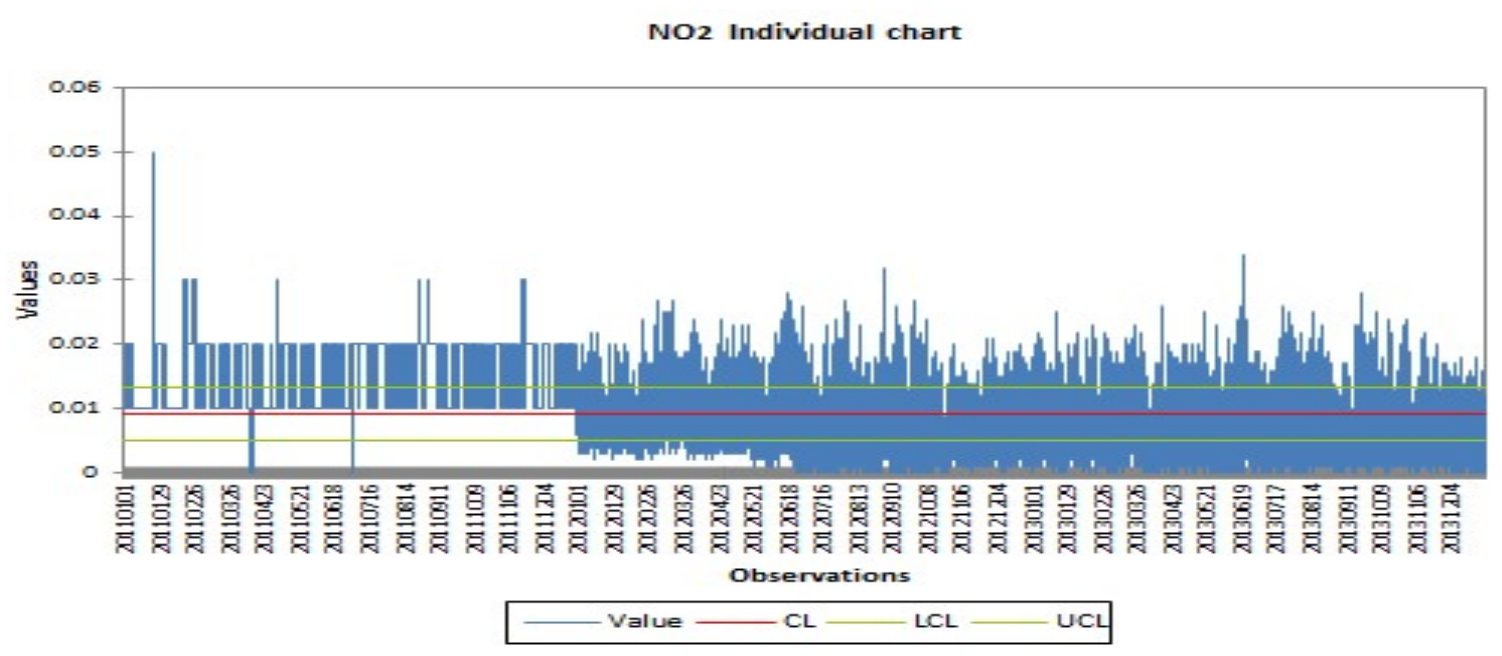

Fig.4. Control chart of $\mathrm{NO}_{2}$ for Kota Kinabalu (2011-2013)

\section{CONCLUSION}

Generally, the chemometric technique is one of the meaningful tool for environmental studies. The large set of environmental data has been simplified by using the chemometric technique. In this study, PCA has been used for sources identification and SPC used for air pollutant trends from 2011 to 2013. From the result, PCA shows that $\mathrm{NO}_{2}, \mathrm{CO}$ and $\mathrm{PM}_{10}$ are primarily emitted from the industrial foundation, land used development and motor vehicle. Hence, this study indicate for the future and effective management in urban town planning, urban transportation planning and air quality management. Urban town panning should control and monitor the expansion of land uses. Other than that, the risk assessment should be done especially for air quality monitoring in the construction sites and industrial sites. Moreover, the transportation planning should recommend or introduce the fuel that produce the complete combustion inside the motor vehicle to prevent the emission of toxic pollutants.

\section{ACKNOWLEDGEMENTS}

This work has been supported in part by the Universiti Kuala Lumpur. The author would like to express her utmost gratitude to all the researchers who have contributed in this study. The author would also like to acknowledge the assistance and advice provided by supervisor, Dr. Ahmad ShakirMohd Saudi. 


\section{REFERENCES}

[1] Leh O L H, MusthafaS N A M, Omar D.Environmental health in relation to urban planning and human physical activity. Malaysian Journal of Analytical Sciences, 2015, 19(4):896-903

[2] Mabahwi N A, Leh O L, Omar D. Human health and wellbeing: Human health effect of air pollution. Procedia-Social and Behavioral Sciences, 2014, 153:221-229

[3] Dominick D, Juahir H, Latif M T, Zain S M, Aris A Z. Spatial assessment of air quality patterns in Malaysia using multivariate analysis. Atmospheric Environment, 2012, $60: 172-1781$

[4] Azid A, Juahir H, Amran M A, Suhaili Z, Osman M R, Muhamad A, Abidin I Z, Sulaiman N H, Saudi A S. Spatial air quality modelling using chemometrics techniques: A case study in Peninsular Malaysia. Malaysian Journal of Analytical Sciences, 2015, 19(6):1415-1430

[5] Azid A, Juahir H, Latif M T, Zain S M, Osman M R. Feed-forward artificial neural network model for air pollutant index prediction in the southern region of Peninsular Malaysia. Journal of Environmental Protection. 2013, 4(12):1-10

[6]Corbett C J, Pan J N. Evaluating environmental performance using statistical process control techniques. European Journal of Operational Research, 2002, 139(1):68-83

[7]Rahman S R, Ismail S N, Raml M F, Latif M T, Abidin E Z, Praveena S M. The assessment of ambient air pollution trend in Klang Valley, Malaysia. World Environment, 2015, 5(1):1-11 [8]Sentian J, Tze O P. Carbon monoxide 'hot-spots' in urban area of Kota Kinabalu City, Sabah. Borneo Science Journal, 8:62-72

[9] Abdullah N A, Shuhaimi S H, Toh Y Y, Shafee A, Maznorizan M. The study of seasonal variation of PM10 concentration in Peninsula, Sabah and Sarawak. Malaysian Meteorological Department, 2011, 9:1-28

[10] Eric J, Yabi Y, Carsten H L. A report on the State of the Environment in Sabah. 2000, http://ww2.sabah.gov.my/jpas/programs/ecd-cab/background/SoE2306.pdf

[11]Chattopadhyay S, Gupta S, Saha R N. Spatial and temporal variation of urban air quality: A GIS approach. Journal of Environmental Protection, 2010, 1(03):264-277

[12] Mutalib S N, Juahir H, Azid A, Sharif S M, Latif M T, Aris A Z, Zain S M, Dominick D. Spatial and temporal air quality pattern recognition using environmetric techniques: A case 
study in Malaysia. Environmental Science: Processes and Impacts, 2013, 15(9):1717-1728

[13] Kamarudin M K, Nalado A M, Kasmuri A, Toriman M E, Juahir H, Umar R, Jamil N R, Saudi A S, Rizman Z I, Gasim M B, Hassan A R. Assessment of river plan changes in Terengganu River using RS and GIS method. Journal of Fundamental and Applied Sciences, $2017,9(2 S): 28-45$

[14] Saudi A S, Kamarudin M K, Ridzuan I S, Ishak R, Azid A, Rizman Z I. Flood risk index pattern assessment: Case study in Langat River basin. Journal of Fundamental and Applied Sciences, 2017, 9(2S):12-27

\section{How to cite this article:}

Hanapiah S M, Saudi A S M, Rizman Z I. Assessment on pattern of urban air quality by using chemometric technique: a case study in kota kinabalu, sabah. J. Fundam. Appl. Sci., 2017, 9(4S), 861-870. 